\title{
Planejamento de metas para redução de falhas no processo de distribuição de uma empresa transportadora
}

\section{Adriano Lindon Leite Cardoso adcardoso@hotmail.com \\ Universidade do Estado do Pará (UEPA), Belém \\ Ywakenon Bento de Melo Souza kennonsouza@hotmail.com \\ Universidade do Estado do Pará (UEPA), Belém \\ Vitor William Batista Martins vitor_engenharia@hotmail.com Universidade do Estado do Pará (UEPA) Belém \\ Fernanda Quitéria Arraes Pimentel \\ Quiteria \\ pimentelfernanda95@gmail.com
Universidade do Estado do Pará (UEPA), \\ Belém}

\author{
RESUMO
}

O sistema de transporte de cargas no Brasil tem sido fator importante na economia do país. Com isso, este é considerado crucial nas cadeias produtivas, o qual apresenta capacidade de fazer a aproximação entre os mercados propiciando a integração entre regiões e estados. Desta forma, esta pesquisa teve como foco propor e definir metas a serem implantadas em uma empresa transportadora de cargas, objetivando melhorias na mesma, por meio do planejamento SMART de metas. A estratégia de pesquisa adotada foi o estudo de caso, pois foi realizado estudo aprofundado do objeto em questão. Como resultados tem-se a identificação das falhas que prejudicam o processo de distribuição da transportadora e, por conseguinte a elaboração e proposição de 3 metas SMART em um horizonte de 1 ano para diminuição de falhas na empresa estudada, um plano de ação 5W1H para dar suporte na efetivação de tais. Como conclusão destaca-se: a importância do método SMART na estruturação de metas para diminuição de falhas no processo produtivo de uma empresa, pois a ferramenta auxilia na criação de um objetivo e a participação necessária de um plano de ação para auxiliar o método SMART, pois deve-se traçar o percurso até a conclusão de metas.
\end{abstract}

PALAVRAS-CHAVE: Gestão Estratégica. Identificação de Falhas. Planejamento Smart. $5 \mathrm{~W} 1 \mathrm{H}$. 


\section{INTRODUÇÃO}

Considerando a intensa competitividade, as organizações procuram formas de viabilizar seus produtos e/ou serviços pela melhoria de seus processos voltados à redução de desperdícios e aumento da produtividade, proporcionando a maximização do lucro. Com a mudança de cenários, as organizações necessitam produzir e fornecer cada vez mais com menos recursos, ocasionando assim uma necessidade de utilização de ferramentas e métodos que permitem a gestão estratégica em qualquer empreendimento. A partir disso, Ramos et al. (2013) afirma ser necessária a procura por métodos adequados que serão aplicados nos processos, com a intenção de que seus objetivos estratégicos sejam repassados ao plano tático e operacional para alcançar de forma eficaz todos os critérios de desempenho.

O transporte rodoviário de cargas apresenta importância indiscutível para qualquer economia, visto que, este é um serviço crucial na cadeia de produção e distribuição tanto de bens industriais quanto agrícolas. De acordo com dados fornecidos pela confederação nacional do transporte (CNT, 2014), o modal rodoviário é responsável pelo fluxo de mais de $60 \%$ de todas as cargas que trafegam no território brasileiro. O sistema de transportes de cargas é, portanto, um ramo de negócio de suma importância na economia do Brasil. Contudo, este é parte fundamental nas cadeias produtivas, sendo que aproxima mercados promovendo a integração entre regiões e estados.

Desta forma, este trabalho teve como objetivo propor metas SMART para redução de falhas no processo de distribuição de mercadorias de uma empresa transportadoras de cargas, localizada na cidade de Marabá-PA onde a população está em constante crescimento e necessita de empresas qualificadas para executarem tal serviço. e criação do plano de ação para alcançar o recomendado.

Para alcançar este objetivo, fez-se necessário utilizar as ferramentas da qualidade (Diagrama de Ishikawa e Diagrama de Pareto) para que auxiliem na gestão de distribuição de cargas, otimizando os processos operacionais da empresa e assim solucionar as principais falhas através da definição de metas SMART.

\section{REVISÃO BIBLIOGRÁFICA}

\section{LOGÍSTICA DE TRANSPORTES}

Segundo Ballou (2007), o ramo de transporte é, sob qualquer ponto de vista, seja político, militar ou econômico, a atividade que apresenta maior importância no mundo. O transporte rodoviário foi fundamental no crescimento produtivo do Brasil, e teve enorme relevância no contexto do desenvolvimento global do País, devido ser um grande indutor de desenvolvimento socioeconômico, em razão da abrangência espacial apresentar características únicas de modo que fosse possível uma maior integração administrativa.

É relevante observar que o modal rodoviário no Brasil, apresenta uma predominância absoluta e o transporte de mercadorias é realizado em sua 
maioria por meio de carretas e caminhões, acontecimento decorrente de um processo histórico.

Novaes (2007), afirma que a origem da logística é iniciada por meio de operações militares, onde relacionava-se com todo processo de aquisição e fornecimento de materiais visando atender todos os objetivos de combate da época. Posteriormente esse conceito se difundiu e começou a ser inserido no ramo empresarial, nesse momento a logística era projetada com objetivo de administrar sistemas, referentes somente a movimentações, visando o controle do transporte dos insumos, produtos acabados e inacabados e também os estoques.

Uma nova concepção entrou em vigor e passou a existir a integração das diversas áreas envolvidas na produção. Devido ao ambiente altamente competitivo e a globalização dos mercados, crescem cada vez mais as exigências em termos de qualidade e produtividade em relação aos serviços oferecidos aos clientes, nesse contexto a logística é crucial para as organizações que visam alcançar seus objetivos.

\section{QUALIDADE}

Com o passar dos tempos, grandes transformações foram verificadas na economia mundial, e estas tem gerado uma nova ordem: a competição. As empresas lutam para conquistar um lugar no mercado cada dia mais competitivo e acirrado e vale a máxima de que sobreviverá a que for melhor.

A busca por esse espaço requer a satisfação dos consumidores com serviços/produtos altamente qualificados. O conceito básico de qualidade está ligado a adequação ao uso e inexistência de defeitos. De acordo com (GOMES; SILVA; VIOLATO, 2006), o sentido da palavra qualidade quer dizer aquilo que caracteriza uma pessoa ou coisa, distinguindo-as das outras, como: atributo, modo de ser, aptidão, disposição, moral dentre outros. Já para Slack, Chambers e Johnston (2009), qualidade é a conformidade, de acordo com as necessidades exigidas pelos consumidores, ou seja, "Fazer certo as coisas".

Por um bom tempo, o termo qualidade era associado unicamente a bens e produtos, todavia, nas últimas décadas com o avanço do setor de serviços muitos métodos de gerenciamento foram surgindo enfocando a qualidade na área da prestação de serviços. Em conformidade com Las Casas (2002), a qualidade nos serviços está diretamente ligada a satisfação do cliente, pois os mesmos perceberam a qualidade voltando a comprar novamente, além de fazer indicações a pessoas que estão em seu ciclo de convivência.

\section{FERRAMENTAS DA QUALIDADE}

Tanto as Indústrias quanto os setores de serviços, há muito tempo, buscam adotar programas de gerenciamento que sejam capazes de oferecer aos seus consumidores produtos e serviços que apresentem qualidade, agregando com custos acessíveis e de produção ecologicamente correta. 
As ferramentas de qualidade são utilizadas comumente como base ao desenvolvimento do fator qualidade ou ao apoio a decisões nas análises feitas em determinados problemas (MIGUEL,2006).

Mata-Lima (2007), afirma ainda, que para a aplicação das ferramentas de qualidade na identificação da causa de problemas, deve acontecer um debate entre os integrantes interessados e que após isso as decisões a serem tomadas sejam fundamentadas de acordo com as informações que foram levantadas.

Segundo Toledo et al (2014), a utilização de ferramentas estatísticas por empresas, está associado a visão de que identificar e remover as causas dos problemas se obtém maior qualidade e produtividade, a isso acrescentado de que as técnicas conhecidas como gráficas e especificas determinam melhores analises do que os processos não estruturados.

Coutinho et al. (2010) complementa que o objetivo principal da aplicação das ferramentas é identificar os maiores problemas por meio das análises adequadas, visando à melhor solução do mesmo.

Afim de melhor estruturar o ambiente em uma organização favorável ao melhoramento da qualidade é necessário utilizar as ferramentas de qualidade, pois essas são definidas especificamente para organizar da melhor maneira possível os dados e informações que serão utilizados no processo. Ressalta-se que todas as áreas envolvidas no processo da empresa devem entender e utilizar as ferramentas de modo a estimular e facilitar o processo de melhoria.

\section{Diagrama de Causa e Efeito}

Segundo Paladini (2005), o diagrama de causa e efeito, também denominado de diagrama de Ishikawa ou espinha de peixe é uma ferramenta de qualidade utilizada para dispor, de forma gráfica, as possíveis causas que levam a um determinado problema no processo. Esta ferramenta é um instrumento muito importante para que se possa descobrir os efeitos indesejados dentro de um processo, a partir disso, aplicar as devidas correções para elimina-los.

Em 1943, foi desenvolvido pelo engenheiro químico Kaoru Ishikawa o diagrama de causa e efeito, na universidade de Tóquio. Este diagrama foi construído com o intuito de demonstrar a alguns engenheiros de uma indústria japonesa como os diversos fatores de um processo estavam interligados. Outro nome dado ao diagrama foi o do próprio criador, o diagrama de Ishikawa. Em conformidade com Ishikawa (1993), este diagrama apresenta um conjunto de fatores de causas com um efeito de qualidade.

A construção do diagrama é feita com a elaboração de um desenho que nos remete a uma "espinha de peixe". O diagrama considera que os problemas podem ser classificados em seis tipos de diferentes causas, são eles: Gerenciamento ou medida (As decisões que são tomadas previamente pode alterar o processo e ser a responsável pela causa do problema), material (A matéria prima aplicada no trabalho que pode ser a geradora do problema), Meio ambiente (o ambiente em que está presente o processo pode favorecer a situações problemáticas), método (utilizado para que seja possível a execução do trabalho), mão de obra (Está ligado ao grau de qualificação do responsável pelo 
processo), máquina (pode estar ligada a falta de manutenção ou utilização de forma errada por parte do operador).

Figura 1 - Modelo do Diagrama de Ishikawa

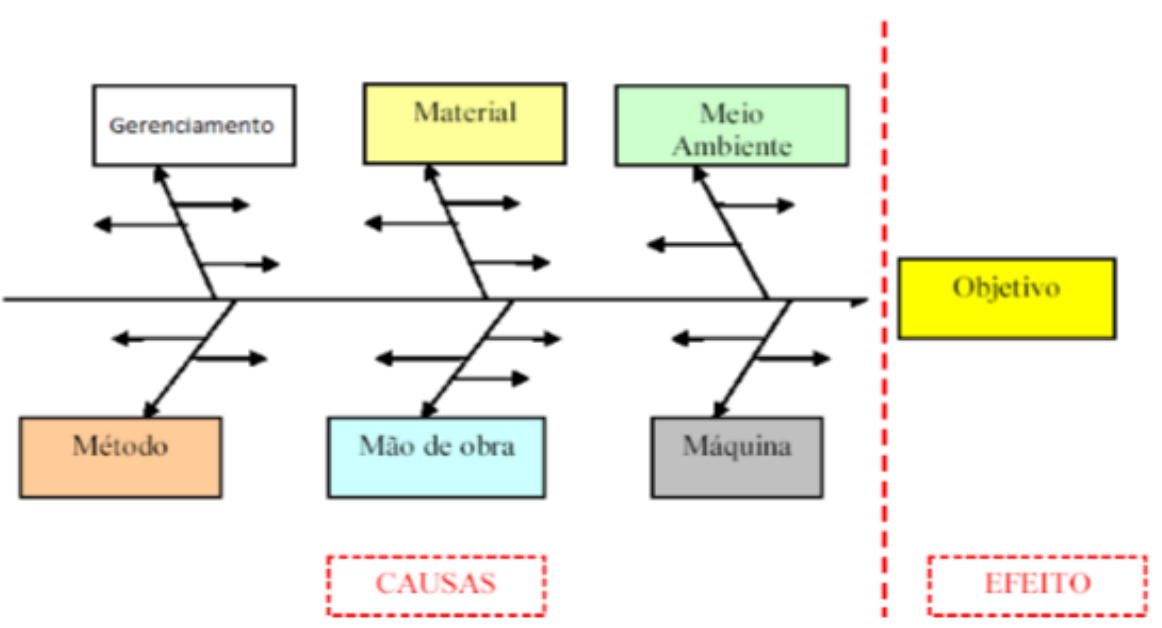

Fonte: Ishikawa (1993)

É perceptível que esta ferramenta de qualidade nos proporciona uma representação de forma lógica, e em ordem de relevância, sendo de suma importância para aplicação no meio gerencial, onde irá facilitar o agrupamento e a fácil visualização das várias causas de um problema.

\section{Diagrama de Pareto}

O gráfico de Pareto consiste em fazer a organização de dados utilizando uma ordem de importância, permitindo que seja determinada as prioridades para resolução das problemáticas. Esta ferramenta da qualidade busca classificar as causas dos defeitos por ordem de frequência, as informações são demonstradas por meio de colunas em que os dados são dispostos em percentuais e distribuídos em ordem decrescente, podendo ainda ser usada uma curva cumulativa.

Para Barreira (2013), o diagrama de Pareto é um gráfico constituído de barras verticais, que irá permitir a determinação dos problemas e suas prioridades, o suporte a ele é dado por uma lista de verificação, onde se colocam os problemas que são encontrados e a frequência com que eles ocorrem. 
Figura 2 - Modelo do Gráfico de Pareto

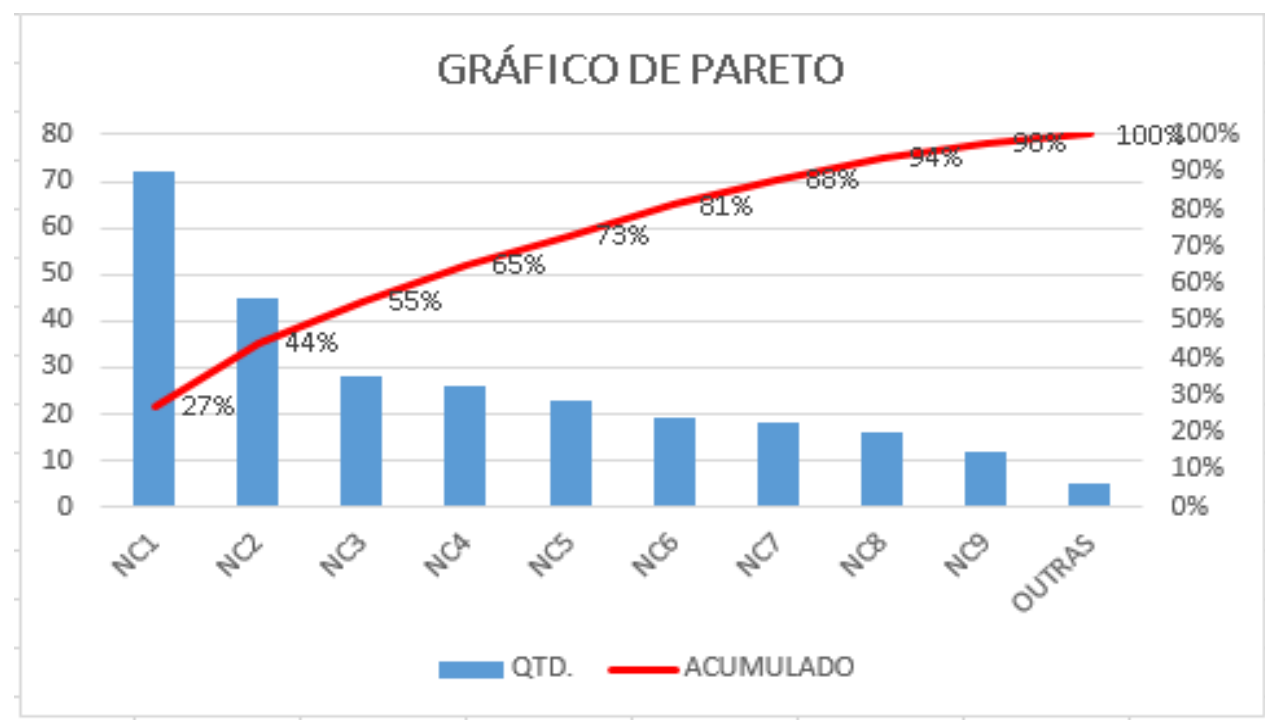

Fonte: Autoria própria (2017)

\section{MÉTODO SMART}

Considerado por diversos autores como o "pai" da administração moderna, Peter Drucker (1909-2005) desenvolveu e aplicou diversos métodos onde se difundiram no mundo dos negócios. De acordo com Pereira (2011), o método SMART foi proposto por Drucker como parte da gestão por objetivos, em seu livro "The Practice of Management" (1954). A gestão por objetivos foi amplamente utilizada pelas maiores empresas do mundo entre 1950 e 1990.

Para Souza (2015), meta SMART é uma ferramenta originalmente criada por Peter Drucker pai da administração moderna, SMART é um anagrama das palavras (em inglês) que definem os cinco conceitos que o formam. Specific (específico), Measurable (mensurável), Attainable (alcançável), Realistics (realistas), Relevant (relevantes) e Time Bound (tempo), ou seja, consecutivamente significam: objetivos específicos, mensuráveis, atingíveis, realísticos e com um prazo determinado para atingi-los.

De acordo com Evans (2013), as metas estão intimamente relacionadas com objetivos, são alvos, seja ao longo do percurso ou no destino final e são normalmente definidas em números. Peter Drucker advertia: "as instituições confundem boas intenções com metas". Não se elas forem SMART, inteligentes.

Definir metas e objetivos realizáveis é uma das diversas responsabilidades que são atribuídas aos afazeres dos gestores, entretanto nem todos conseguem resultados positivos nessas tarefas o que pode ocasionar grandes problemas, com isso uma ferramenta de gestão que possui capacidade tanto para auxiliar quanto desenvolver propósitos é a metodologia SMART.

\section{PLANO DE AÇÃO - 5W1H}

O plano de ação consiste em planejar todas as ações necessárias visando atingir o resultado desejado, apresentando como objetivo planejamento das 
ações que deverão bloquear as causas fundamentais do problema para que o mesmo não venha a ocorrer novamente. Em conformidade com (DOS SANTOS et al, 2011), Plano de ação ou 5W1H é uma ferramenta utilizada para planejar uma determinada ação que será tomada, na qual possui competência para orientar as inúmeras ações que serão executadas, podendo ainda ser adotada na descrição de algum problema do qual se tenha a necessidade de elaborar um aprofundamento mais amplo para que seja possível alcançar a sua causa raiz.

Para Lisbôa e Godoy (2012), o método 5W1H é uma ferramenta que consiste em realizar uma série de questionamentos voltados principalmente ao processo de produção que irá permitir identificar quais as atividades mais relevantes, e após isso, constatar os seus problemas e apontar possíveis soluções para estes.

A ferramenta mais aplicada para a elaboração de um plano de ação é a 5W1H (Marshall Junior et al, 2006), onde está é representada pelas iniciais em inglês, das perguntas:

$$
\begin{aligned}
& \text { - What-O que? } \\
& \text { - Who-Quem? } \\
& \text { - When-Quando? } \\
& \text { - Where-Onde? } \\
& \text { - Why-Por que? } \\
& \text { - How-Como? }
\end{aligned}
$$

Geralmente este plano de ação é apresentado em uma tabela, no qual em cada coluna são colocadas as perguntas relacionadas ao $5 \mathrm{~W} 1 \mathrm{H}$, conforme ilustrado no Quadro 1:

Quadro 1 - Modelo 5W1H

\begin{tabular}{|c|c|c|c|c|c|}
\hline O que? & Como? & Por que? & Quem? & Quando? & Onde? \\
\hline $\begin{array}{c}\text { Determinar } \\
\text { as ações }\end{array}$ & Descrever & Justificar & & & \\
que devem & como será & o por que & Identificar a & Estabelecer & Declarar \\
ser & feito para & é & equipe & prazo & onde \\
realizadas, & alcançar & necessário & responsável & será \\
ou seja, o & determinadização & fazer esta & pelas ações. & da ação. & a tarefa. \\
que deve & ação & ação. & & & \\
ser feito. & & & & & \\
\hline
\end{tabular}

Fonte: adaptado de Marshall Junior et al (2006) 
Para a elaboração do presente estudo, foi realizado apanhado bibliográfico referente ao tema proposto, utilizando artigos publicados em congressos e simpósios, revistas e apostilas cientificas, monografias e dissertações.

Segundo Gil (2008), o método cientifico é um conjunto de procedimentos intelectuais e técnicos, no qual são adotados para se atingir o conhecimento. Para que possa ser considerado conhecimento cientifico, deve ser identificado os passos para a sua verificação, ou seja, expor o método em que possibilitou alcançar o conhecimento almejado.

\section{ESTRATÉGIA DE PESQUISA}

A estratégia de pesquisa adotada para a realização deste trabalho foi o estudo de caso. De acordo com Gil (2008), o estudo de caso caracteriza-se por ser um aprofundado e exaustivo procedimento de pesquisa do objeto em questão, no qual pode ser feito um amplo e detalhado conhecimento acerca das tarefas que são consideradas quase que impossíveis para ser executadas por meio de outros delineamentos.

\section{CLASSIFICAÇÃO DA PESQUISA}

A pesquisa é o procedimento racional e sistemático, que se desenvolve ao longo de um processo, mediante os conhecimentos disponíveis e a utilização cuidadosa de métodos e técnicas, com o objetivo de proporcionar respostas aos problemas propostos (GIL, 2002).

Ainda de acordo com Gil (2002), as pesquisas são apresentadas em duas categorias: A básica, no qual tem como finalidade reunir estudos com o intuito único de fazer o preenchimento de uma área no conhecimento, além da aplicada, onde neste tipo de pesquisa os estudos são elaborados com o propósito de resolver problemáticas no âmbito das sociedades em que os pesquisadores estão presentes.

Em termos de classificação em relação a sua natureza, a pesquisa realizada é considerada do tipo Aplicada. Em consonância com Silva e Menezes (2005), este tipo de pesquisa é aquela em que se objetiva determinar conhecimentos para serem aplicados de forma prática, no qual estes são direcionados as resoluções de um problema considerado especificam.

Quanto à forma de abordagem, possui características fortes de uma pesquisa qualitativa, em virtude de que os dados que foram coletados são predominantemente oriundos de entrevistas e observações diretas. Para Silva e Menezes (2005), a pesquisa qualitativa determina uma relação existente entre o mundo real e o sujeito, ou seja, existe um vínculo entre o mundo objetivo e a subjetividade, onde estes não podem ser traduzidos numericamente.

Do ponto de vista dos seus objetivos a pesquisa se caracteriza como descritiva. Segundo Gil (2008), a pesquisa descritiva visa descrever as características de um determinado fenômeno entre as variáveis escolhidas, no qual utiliza técnicas padronizadas de coleta de dados. 


\section{DELINEAMENTO DA PESQUISA}

A empresa estudada está situada na cidade de Marabá, no estado do Pará. A organização atua há sete anos no mercado de transportes de cargas, e localiza-se no núcleo Nova Marabá, na folha 33. Conta com um quadro fixo de 7 funcionários, porém existem períodos em que tem-se mais pessoas, visto que a organização trabalha com contratação temporária de trabalhadores.

O empreendimento considera que existem apenas 3 setores no seu interior: escritório, garagem e portaria; 2,3 e 2 funcionários respectivamente.

Atua apenas com o transporte de mercadorias, oferecendo somente este serviço, não trabalha com armazenamento de produtos por longo período, podendo ficar com estes apenas em um curto prazo e alocados dentro dos caminhões, ou seja, apenas o tempo necessário para que o transporte possa ser realizado.

A partir da definição metodológica, foi possível fazer o delineamento das etapas da pesquisa, presentes na Figura 3.

Figura 3 - Etapas da pesquisa

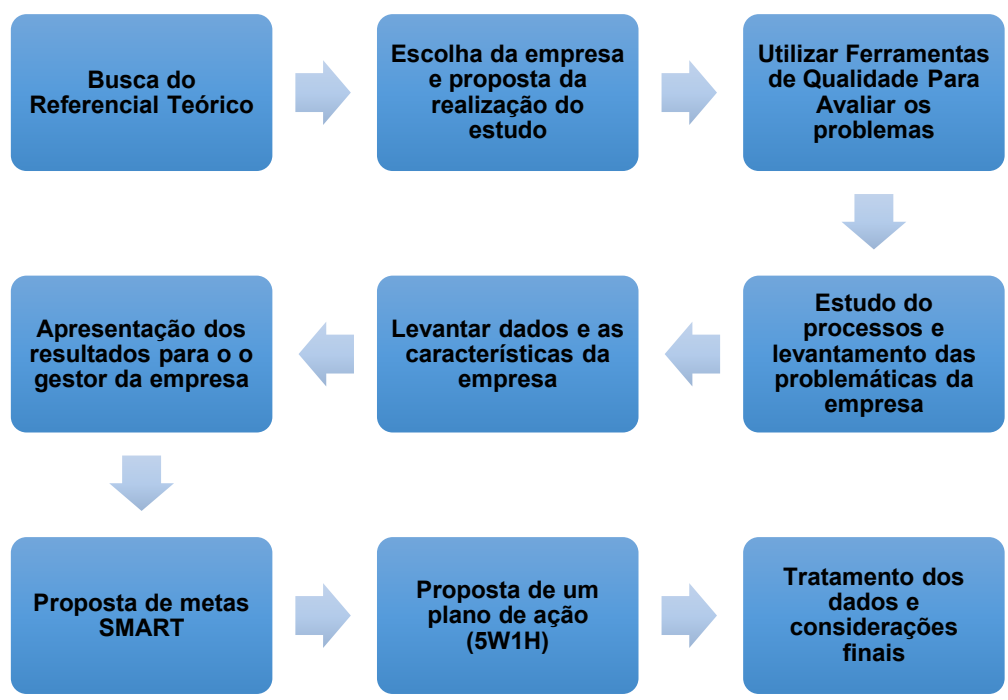

Fonte: Autoria própria (2017)

\section{ETAPAS DA PESQUISA}

O trabalho foi realizado em 7 etapas, sendo que a primeira refere-se a delimitação e elaboração dos seguintes elementos: Justificativa; Objetivos; Estrutura de Qualificação e Metodologia.

A segunda etapa é referente ao embasamento teórico da pesquisa: levantamento bibliográfico considerando artigos, livros, dissertações de mestrados, trabalhos de conclusão de curso e outras publicações que foram de suma importância para a realização da metodologia proposta.

A terceira tarefa é a escolha da empresa e a proposição de realização do estudo na mesma, devido necessitar o consentimento do proprietário, pois será realizado estudo no local e a necessidade de apuração e dados através de entrevista com o mesmo. 
O levantamento de dados e das características da empresa foram adquiridos por meio da entrevista com o dono da organização, onde todas as informações relevantes ao trabalho foram entregues. Ressalta-se que no primeiro contato o proprietário direcionou a metodologia para o setor de distribuição de cargas.

O levantamento de problemas e o estudo, sendo a quinta etapa destes passou pelas seguintes fases:

- Conhecimento das etapas que envolvem o processo de distribuição de cargas;

- Levantamento dos maiores problemas verificados na empresa;

- Analise e identificação de fatores e priorização de problemáticas por meio de ferramentas de qualidade: Diagrama de Ishikawa e Pareto.

Os dados apurados serão organizados por meio de gráficos, tabelas e quadros, o software Microsoft Excel será utilizado, pois permite a manipulação e tratamento de dados que foram alcançados com o decorrer da pesquisa.

A sexta etapa é referente à proposição de soluções dos problemas identificados pelo uso das ferramentas da qualidade, onde a aplicação em conjunto destas força o descobrimento dos problemas, facilitando no momento de criação e meta SMART, que serão alcançadas com o auxilio do plano de ação $5 \mathrm{~W} 1 \mathrm{H}$.

Após a realização das análises dos dados obtidos, ocorre a apresentação ao proprietário da Transportadora de cargas, onde serão apresentados não somente as metas, mas também o plano de ação, ocorrendo à explanação de cada tópico.

No que se refere à avaliação qualitativa, será utilizado à aplicação de entrevista com o responsável pela empresa, onde todas as informações serão anotadas em um caderno, e posteriormente repassadas para um computador com o auxílio de programas específicos. Além da interação entre entrevistadores - acadêmicos realizadores da pesquisa - e entrevistado - proprietário da empresa -, será fornecido para a equipe de pesquisa um histórico sobre a transportadora de cargas, o qual a análise documental fornecerá maior contato com as informações relacionadas à empresa.

\section{Tratamento de Dados}

Os dados foram coletados dentro da empresa estudada com apoio do gestor e dono. Cada ferramenta da qualidade era preenchida inicialmente em um esboço de sua metodologia, ou seja, as observações eram apenas anotadas e verificou-se o que eram causas para preenchimento de Ishikawa.

As anotações do Diagrama de Pareto eram alocadas em planilhas impressas para diagnóstico de quantidade de cada efeito ocorrido e encontrado após a utilização do diagrama de espinha de peixe.

Os dados foram tratados no Microsoft Excel, onde foram geradas tabelas e figuras para ilustrar a quantidade de problemáticas que ocorriam e quais deveriam ser tratadas inicialmente. 


\section{APRESENTAÇÃO DA EMPRESA}

Empresa localizada no município de Marabá, núcleo nova marabá, atua há 7 anos no mercado e conta com um quadro de 7 funcionários, sendo que ocorre a existência de funcionários diaristas, para quando ocorrem problemas com funcionários ou existe um aumento no número de cargas, diaristas estes chamados popularmente de "chapas".

A frota de caminhões é totalmente terceirizada, existindo apenas uma unidade física para controle de logística, que funciona como posto de auxilio contando com área de garagem para os carros e dormitório para funcionários.

\section{LEVANTAMENTO DE PROBLEMA DA EMPRESA}

Neste tópico apresenta-se o diagnóstico de quais são as principais problemáticas dentro da empresa estudada. Apresentam-se as ferramentas utilizadas para diagnóstico (Digramas de Ishikawa e Pareto).

\section{Diagrama de Ishikawa}

A empresa estudada trabalha com a parte referente a ponto de distribuição de cargas, o processo de entrega, devido este fato a primeira ferramenta da qualidade objetivou-se em avaliar apenas os tópicos problemáticos e suas causas que afetam no desempenho desta atribuição do objeto de estudo.

Figura 4 - Diagrama de Ishikawa

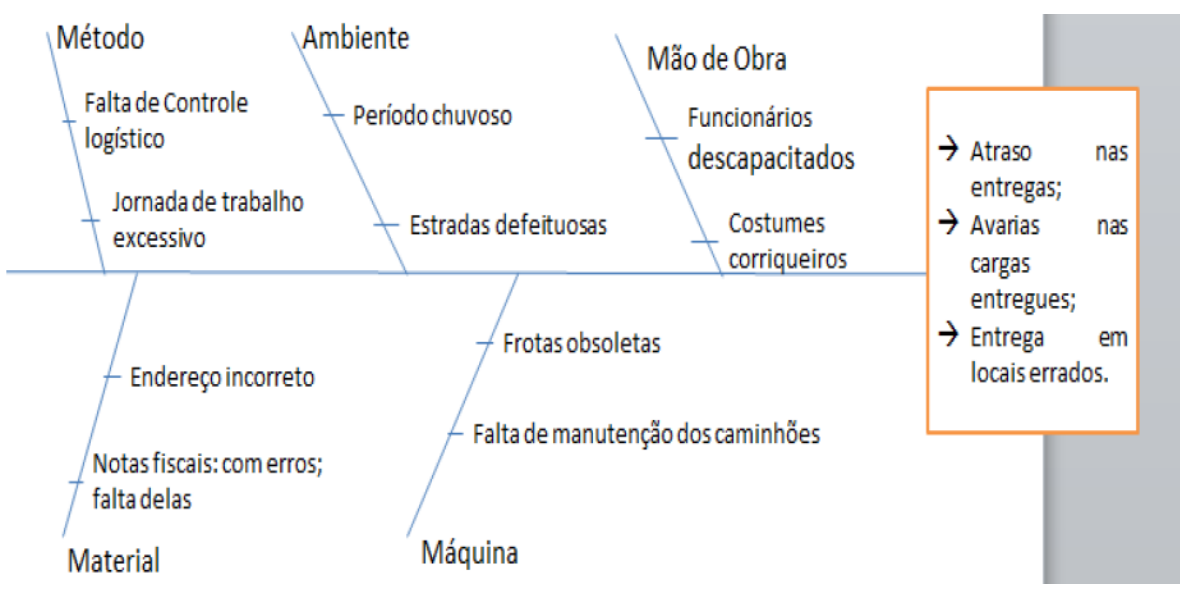

Fonte: Autoria própria (2017)

O diagrama de Ishikawa apresentado pela Figura 4, apresenta apenas 5 causas para os efeitos decorrentes na organização estudada, porém não implica em erro, pois esta ferramenta da qualidade não tem uma forma padrão colocando a quantidade mínima de causas, apenas que existem causas influenciando diretamente em um efeito, ou seja, o problema. 
Apareceram durante a pesquisa realizada pelo trabalho, três defeitos como podem ser vistos na Figura 4, isto se deve ao fato de todos eles terem conexões entre si, e tendo a conectividade das causas.

O primeiro efeito foi o atraso de entregas, ou seja, as entregas passam do período limite que devem ser entregues, gerando insatisfação e assim resultando em queda de qualidade sobre o ponto de vista do cliente.

A segunda problemática é referente as avarias no produto entregue, tendo em consideração o fato de realização apenas de transporte de itens, a parte física deste deve ser entregue ao consumidor daquele serviço da maneira em que foi recebida pela empresa de transporte.

Entrega em locais errados é o terceiro problemas, porém não menos importante em relação aos outros, pois acarreta em necessidade de continuar transportando o material e assim aumentando a possibilidade de avarias, podendo ultrapassar a data estabelecida em contrato para realização do transporte.

\section{Diagrama de Pareto}

A construção do Gráfico de Pareto necessita do reconhecimento da quantidade de falhas ocorridas durante o processo de estudo, ocorrido no período entre o mês de novembro de 2016 a Abril de 2017. A Tabela 1 expõe as quantidades de cada defeito.

Tabela 1 - Quantidade de defeitos

\begin{tabular}{cccc} 
Mês & $\begin{array}{c}\text { Avaria nas cargas } \\
\text { entregues }\end{array}$ & $\begin{array}{c}\text { Defeitos } \\
\text { Atraso nas entregas }\end{array}$ & $\begin{array}{c}\text { Entrega em locais } \\
\text { errados }\end{array}$ \\
\hline Novembro & 3 & 2 & 2 \\
Dezembro & 4 & 2 & 2 \\
Janeiro & 3 & 4 & 3 \\
Fevereiro & 4 & 3 & \\
Março & 2 & 3 & 1 \\
Abril & 2 & 3 & 2 \\
TOTAL & 18 & 17 & 1 \\
\hline
\end{tabular}

Fonte: Autoria própria (2017)

Com base na Tabela 1, pode-se dar continuidade no estudo relacionado a esta ferramenta de qualidade, onde foram alocados os totais de problemas.

O diagrama de Pareto trabalhado é apresentado pela Tabela 2 e Figura 5, utilizaram as problemáticas que foram encontradas a partir da utilização do diagrama de causa e efeito.

As duas figuras complementam-se e estão inseridas desta forma devido o fato desta ferramenta necessitar de uma listagem de problemas ocorridos e posteriormente a criação de gráfico. 
Tabela 2 - Tabela de Pareto

\begin{tabular}{|c|c|c|c|c|}
\hline Defeito & Quantidade & $\begin{array}{l}\text { Quantidade } \\
\text { acumulada }\end{array}$ & $\%$ & $\%$ acumulada \\
\hline $\begin{array}{c}\text { Avaria nas cargas } \\
\text { entregues }\end{array}$ & 18 & 18 & $39 \%$ & $39 \%$ \\
\hline $\begin{array}{c}\text { Atraso nas } \\
\text { entregas }\end{array}$ & 17 & 35 & $37 \%$ & $76 \%$ \\
\hline $\begin{array}{c}\text { Entrega em locais } \\
\text { errados }\end{array}$ & 11 & 46 & $24 \%$ & $100 \%$ \\
\hline TOTAL & 46 & & $100 \%$ & \\
\hline
\end{tabular}

Fonte: Autoria própria (2017)

Tendo como base a Tabela 1, pertencente ao diagrama de Pareto, com base nas informações pode-se criar o gráfico da Figura 5.

Figura 5 - Diagrama de Pareto

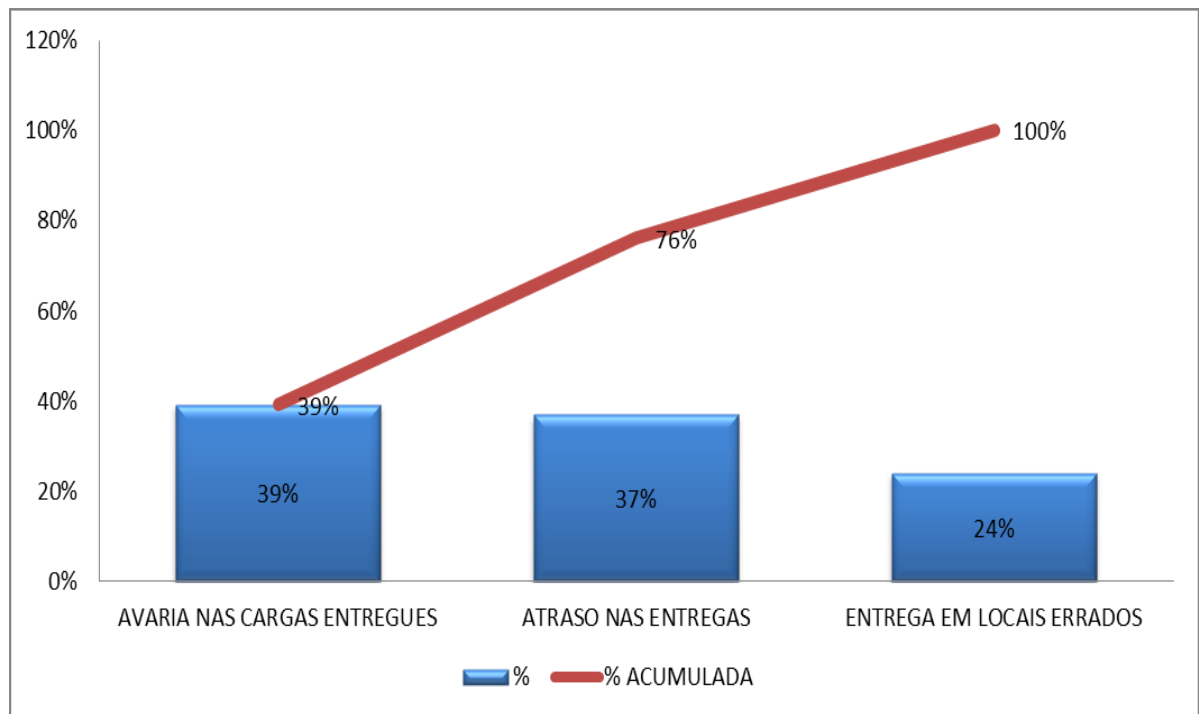

Fonte: Autoria própria (2017)

A partir da Figura 5, verificou-se o tópico avaria nas cargas entregues como representante do maior percentual de falhas, sendo este o tópico em que metas foram planejadas inicialmente para resolução, pois representa uma proposição de melhoria de $39 \%$ de diminuição de problemas.

\section{PROPOSTA DE RESOLUÇÃO DAS PROBLEMÁTICAS LEVANTADAS}

A partir da Figura 5, verificou-se o tópico avaria nas cargas entregues como representante do maior percentual de falhas, sendo este o tópico em que metas foram planejadas inicialmente para resolução, pois representa uma proposição de melhoria de $39 \%$ de diminuição de problemas. 
O quadro 2 apresenta como a meta SMART deve ser fabricada antes de ser estruturada e apontada como a metodologia diz que ela deve ser apresentada, posteriormente ao Quadro 2 os fragmentos são unidos e as metas SMART são apontadas.

Quadro 2 - Fragmentos Metas SMART

\begin{tabular}{|c|c|c|}
\hline Ffagmento 1a Meta & Fragmento 2a Meta & Fragmento 3a Meta \\
\hline 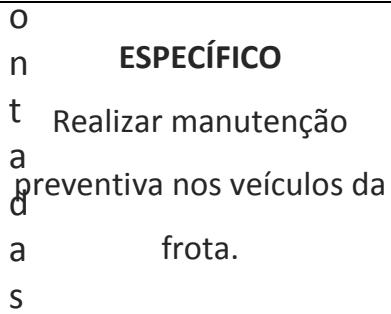 & $\begin{array}{c}\text { ESPECÍFICO } \\
\text { Elaborar plano logístico } \\
\text { em médio prazo, } \\
\text { aplicando roteirização de } \\
\text { veículos. }\end{array}$ & $\begin{array}{c}\text { ESPECífICO } \\
\text { Aplicar o uso de novas } \\
\text { ferramentas tecnológicas de } \\
\text { localização (GPS). }\end{array}$ \\
\hline $\begin{array}{l}\text { MENSURÁVEL } \\
\text { Em um período de } 6 \text { em } 6 \\
\text { meses, iniciando no mês } \\
\text { de Maio/17. }\end{array}$ & $\begin{array}{c}\text { MENSURÁVEL } \\
\text { Em um período de } 1 \text { ano, } \\
\text { iniciando no mês de } \\
\text { Junho/17. }\end{array}$ & $\begin{array}{c}\text { MENSURÁVEL } \\
\text { Em um período de } 6 \text { meses, } \\
\text { iniciando no mês de Maio/17. }\end{array}$ \\
\hline $\begin{array}{l}\text { R ATINGÍVEL } \\
\text { Pretendendo reduzir em } \\
\text { F } 40 \% \text { o número de } \\
\text { F }_{\text {produtos entregues com }} \\
\text { mavarias em um período de } \\
\text { t } \quad 20 \text { meses. } \\
\text { e } \quad\end{array}$ & $\begin{array}{c}\text { ATINGÍVEL } \\
\text { Almejando minimizar o } \\
\text { atraso das entregas em } \\
25 \% .\end{array}$ & $\begin{array}{c}\text { ATINGÍVEL } \\
\text { Pretendendo diminuir em } \\
\text { 20\%, o número de entregas } \\
\text { em locais errados. }\end{array}$ \\
\hline $\begin{array}{l}\text { : } \\
\text { Almejando um maior grau } \\
A^{\text {ilm }} \\
\text { ıde satisfação dos clientes, } \\
t \quad \text { para com o serviço } \\
\text { o } \\
\text { r prestado, fazendo com a } \\
\text { i organização maximize o } \\
\text { a } \\
\text { p número de clientes } \\
r \quad \text { fidelizados. }\end{array}$ & $\begin{array}{l}\text { RELEVANTE } \\
\text { Objetivando eliminar } \\
\text { falhas no processo de } \\
\text { encaminhamento dos } \\
\text { produtos. }\end{array}$ & $\begin{array}{c}\text { RELEVANTE } \\
\text { Visando minimizar custos com } \\
\text { movimentação e retrabalho } \\
\text { nas entregas, além de } \\
\text { diminuir movimentações } \\
\text { adicionais com os produtos. }\end{array}$ \\
\hline $\begin{array}{l}\text { ó } \\
\mathrm{p} \\
\mathrm{r} \\
\mathrm{i} \quad \text { TEMPO } \\
\text { a Iniciando em Maio/17 e } \\
\text { finalizando em Janeiro/19. } \\
2 \\
0 \\
1\end{array}$ & $\begin{array}{c}\text { TEMPO } \\
\text { Iniciando no mês de } \\
\text { Junho/17 e finalizando no } \\
\text { mês de Junho/18. }\end{array}$ & $\begin{array}{c}\text { TEMPO } \\
\text { Iniciando no mês de Maio/17 } \\
\text { e finalizando no mês de } \\
\text { Julho/17. }\end{array}$ \\
\hline
\end{tabular}

Fonte: Autoria própria (2017) 
De acordo com o Quadro 2, a primeira meta SMART definida é realizar manutenção preventiva (de seis em seis meses) nos veículos da frota, iniciando no mês de Maio/17 e finalizando no mês de Janeiro/19. Pretendendo reduzir em $40 \%$ o número de produtos entregues com avarias em um período de 20 meses. Almejando um maior grau de satisfação dos clientes, para com o serviço prestado, ocasionando que a organização maximize o número de clientes fidelizados.

Já a segunda meta SMART compreende elaborar plano logístico em médio prazo, aplicando roteirização de veículos. Em um período de 12 meses, iniciando no mês de Junho/17 e finalizando no mês de Junho/18. Almejando minimizar o atraso das entregas em $25 \%$. Objetivando eliminar falhas no processo de encaminhamento dos produtos.

E como terceira meta SMART definiu-se aplicar o uso de novas ferramentas tecnológicas de localização (GPS). Em um período de seis meses, iniciando no mês de Maio/17 e finalizando no mês de Outubro/17. Visando minimizar custos com movimentação e retrabalho nas entregas, além de diminuir movimentações adicionais com os produtos. Pretendendo diminuir em 20\%, o número de entregas em locais errados.

\section{Plano de Ação - 5W1H}

O quadro 3, apresenta o plano de ação que tem como objetivo dar suporte ao gestor no momento em que as metas forem aplicadas.

Quadro 3 - Plano de Ação 5W1H

\begin{tabular}{|c|c|c|c|c|c|}
\hline O que? & Como? & Por que? & Quem? & Quando? & Onde? \\
\hline $\begin{array}{c}\text { Realizar } \\
\text { manutenção } \\
\text { preventiva } \\
\text { nos veículos } \\
\text { da frota. }\end{array}$ & $\begin{array}{c}\text { Estabelecen } \\
\text { do um plano } \\
\text { de } \\
\text { manutenção } \\
\text { preventiva } \\
\text { que } \\
\text { ocorrerá de } \\
\text { seis em seis } \\
\text { meses. }\end{array}$ & $\begin{array}{l}\text { Para eliminar } \\
\text { falhas no que } \\
\text { diz respeito a } \\
\text { produtos com } \\
\text { avarias. }\end{array}$ & $\begin{array}{c}\text { Setor de } \\
\text { Manutençã } \\
\text { o. }\end{array}$ & $\begin{array}{l}\text { Inicio no } \\
\text { mês de } \\
\text { Maio/17 } \\
\text { finalizand } \\
\text { o no mês } \\
\text { Janeiro/1 } \\
9 .\end{array}$ & $\begin{array}{c}\mathrm{Na} \\
\text { empresa } \\
\text { estudada }\end{array}$ \\
\hline $\begin{array}{c}\text { Aplicar } \\
\text { roteirização } \\
\text { de veículos. }\end{array}$ & $\begin{array}{c}\text { Desenvolve } \\
\text { ndo plano } \\
\text { logístico. }\end{array}$ & $\begin{array}{c}\text { Objetivando } \\
\text { eliminar falhas } \\
\text { no processo de } \\
\text { encaminhamen } \\
\text { to dos } \\
\text { produtos. }\end{array}$ & $\begin{array}{l}\text { Setor de } \\
\text { Logística }\end{array}$ & $\begin{array}{l}\text { Iniciando } \\
\text { no mês } \\
\text { de } \\
\text { Junho/17 } \\
\text { e } \\
\text { finalizand }\end{array}$ & $\begin{array}{c}\mathrm{Na} \\
\text { empresa } \\
\text { estudada }\end{array}$ \\
\hline
\end{tabular}




\begin{tabular}{|c|c|c|c|c|c|}
\hline & & & & $\begin{array}{c}\text { o no mês } \\
\text { de } \\
\text { Junho/18. }\end{array}$ & \\
\hline $\begin{array}{l}\text { Aplicar o uso } \\
\text { de novas } \\
\text { ferramentas } \\
\text { tecnológicas } \\
\text { de } \\
\text { localização. }\end{array}$ & $\begin{array}{l}\text { Adquirindo } \\
\text { GPS e } \\
\text { instalando } \\
\text { nos veículos } \\
\text { da frota. }\end{array}$ & $\begin{array}{c}\text { Para minimizar } \\
\text { entregas em } \\
\text { locais errados, } \\
\text { visto que com o } \\
\text { uso do GPS a } \\
\text { localização da } \\
\text { residência dos } \\
\text { clientes será } \\
\text { mais especifica. }\end{array}$ & Setor de TI & $\begin{array}{c}\text { Iniciando } \\
\text { no mês } \\
\text { de } \\
\text { Maio/17 } \\
\text { e } \\
\text { finalizand } \\
\text { o no mês } \\
\text { de } \\
\text { Julho/17. }\end{array}$ & $\begin{array}{c}\mathrm{Na} \\
\text { empresa } \\
\text { estudada }\end{array}$ \\
\hline
\end{tabular}

Fonte: Autoria própria (2017)

O plano de ação serve como suporte para quando as metas SMART forem propostas ter um meio para se alcança-las, ou seja, saber o que fazer, como fazer, quando fazer e onde fazer e todas as outras perguntas do $5 \mathrm{~W} 1 \mathrm{H}$.

\section{CONCLUSÕES E SUGESTÕES}

A aplicação das ferramentas da qualidade, metodologia SMART e plano de ação serviram para alcançar o objetivo geral de colocação de metas para diminuir falhas. As ferramentas: Pareto e Ishikawa serviram para alcance das problemáticas e suas hierarquizações. A metodologia SMART a proposição de metas, o plano de ação $5 \mathrm{~W} 1 \mathrm{H}$ é colocado para dar suporte às metas estabelecidas.

O trabalho em questão mostrou-se satisfatório quanto a análise e proposição de metas, pois apresenta possíveis melhorias. Os resultados e analises do estudo de caso foram apresentados ao principal gestor da empresa, o proprietário, este entendeu as metas estipuladas, que foram explicadas assim como todas as ferramentas utilizadas, para não existir duvidas durante o possível uso da organização de tudo que foi estudado.

Acredita-se que o principal problema de aplicação das metas propostas e utilização do plano de ação é o recurso humano, pois as metas necessitam de entendimento dos colaboradores que devem trabalhar em conjunto com a gestão e compreender seu papel no decorrer do período em que as metas foram estabelecidas. 
Como proposta de trabalho futuro, sugere-se a verificação de como as metas propostas estão sendo utilizadas pela empresa estudada, verificando onde estão ocorrendo problemas na aplicação das metas SMART.

Foi utilizado no trabalho o setor de entrega de mercadoria, o frete, porém a metodologia proposta pode ser utilizada em outras áreas da mesma organização, ocorrendo à soma de outras ferramentas com as já utilizadas.

Além de um estudo de metodologia Lean, para verificação de quais das sete grandes perdas ou setes desperdícios ocorrem, após isso utilização de ferramentas e métodos para diminui-las e extingui-las. 


\title{
Planning of targets to reduce faults in the process of distribution of a transportation company
}

\begin{abstract}
The cargo transportation system in Brazil has been an important factor in the country's economy. As a result, it is considered crucial in the productive chains, which has the capacity to bring markets closer together, fostering integration between regions and states. In this way, this research aimed to propose and define goals to be implemented in a freight forwarding company, aiming at improvements in it, through SMART goal planning. The research strategy adopted was the case study, since an in-depth study of the object in question was carried out. As results we have the identification of the failures that undermine the carrier distribution process and, consequently, the elaboration and proposition of 3 SMART goals within a 1-year horizon to reduce failures in the company studied, a $5 \mathrm{~W} 1 \mathrm{H}$ action plan to give Support in the accomplishment of such. As a conclusion, it is important to note the importance of the SMART method in structuring goals to reduce failures in the productive process of a company, since the tool assists in the creation of a goal and the necessary participation of a plan of action to assist the SMART method, Because the path must be traced to the completion of goals.
\end{abstract}

KEYWORDS: Strategic Sanagement. Fault Identification. Smart Planning. 5W1H. 
BALLOU, R. H. Logística empresarial: transportes, administração de materiais, distribuição física. São Paulo: Atlas, 2007.

BARREIRA, M. Gestão e Engenharia da Qualidade. Wise Consultoria e Treinamentos, 2013.

CNT. Confederação Nacional do Transporte. Atlas do Transporte 2006. Disponível em: http://www.cnt.org.br>. Acesso em: Nov.2016.

CNT. Confederação Nacional do Transporte. Plano CNT de Logística. Brasília, DF, 2014.

COUTINHO, et al. Contribuição associadas à aplicação integrada das ferramentas da qualidade: O ciclo PDCA como base para resolução de problemas nos processos de produção. In: Simpósio de Engenharia de Produção, 17. 2010, Bauru (SP). Anais... Bauru (SP) SIMPEP, 2010.

DOS SANTOS, D. S., CECCATO, M. S., MICHELON, M. H. Eficiência da ferramenta 8D aplicada em uma indústria do setor metal-mecânico - estudo de caso. FAE Centro Universitário Curso de Engenharia de Produção. Curitiba, 2011.

EVANS, V. Ferramentas estratégicas: guia essencial para construir estrátegias relevantes/Vaughan Evans; tradução Sabine Holler.-1.ed. Rio de Janeiro: Elsevier,2013.

GIL, A. C. Como elaborar projetos de pesquisa. 4o ed. São Paulo: Atlas, 2002. Métodos e Técnicas de Pesquisa Social. 6 ed. São Paulo:

Atlas,2008.

GOMES D. C. S.; SILVA G. R.; VIOLATO R. D. M. Qualidade no atendimento: Supermercado Santa Laura, 2006 Monografia. (Curso de Administração) - Centro Universitário Católico Salesiano Auxilium. Lins.

ISHIKAWA, K. Controle de Qualidade Total: à maneira japonesa. Rio de Janeiro: Campos, 1993.

LAS CASAS, A. L. Marketing de serviços. 3. ed. São Paulo: Atlas, 2002. 
LISBÔA, M. G. P.; GODOY, L. P. Aplicação do método 5W2H no processo produtivo do produto: a joia. Iberoamerican Journal of Industrial Engineering. Florianópolis, v. 4, n. 7, 2012.

MARSHALL JUNIOR, I.; CIERCO, A. A.; ROCHA, A. V.; MOTA, E. B.; LEUSIN, S. Gestão da Qualidade. 7 ed. Rio de Janeiro: FGV, 2006.

MATA-LIMA, H. Aplicação de Ferramentas da Gestão da Qualidade e Ambiente na Resolução de Problemas. Apontamentos da Disciplina de Sustentabilidade e Impactes Ambientais. Universidade da Madeira (Portugal), 2007.

MIGUEL, P.A.C. Qualidade: enfoques e ferramentas. 1 ed. São Paulo: Artliber, 2006.

NOVAES, A. G. Logística e gerenciamento da cadeia de distribuição. Rio de Janeiro: Elsevier, 2007

PALADINI, E.P.; BOUER, G.; FERREIRA, J.J.A.; CARVALHO, M.M.; MIGUEL, P.A.C.; SAMOHYL, R.W.; ROTONDARO, R.G. Gestão da Qualidade: Teoria e Casos. Rio de Janeiro: Elsevier, 2005.

PEREIRA, M. SMART: Como Peter Drucker Formulava Objetivos. Disponível em < http://mp.adm.br/?p=287> Acesso em 15/11/2016.

RAMOS, A. W.; RIBEIRO, C. O.; MIYAKE, D. I.; NAKANO, D.; LAURINDO, F. J. B.; HO, L. L.; CARVALHO, M. M.; BRAZ, M. A.; BALESTRASSI, P. P.; ROTONDARO, R. G. Seis Sigma: Estratégia Gerencial para a Melhoria de Processos, Produtos e Serviços. São Paulo: Atlas, 2013.

SILVA, E. L. MENEZES, E. M. Metodologia da Pesquisa e Elaboração de Dissertação. 4. ed. Florianópolis: UFSC, 2005.

SLACK, N; CHAMBERS, S; JOHNSTON, R. Administração da Produção.3. ed. São Paulo: Atlas, 2009.

SOUZA, Gilson. A fórmula do sucesso/ Gilson Souza. Ed. Clube de autores. Rio de Janeiro: Instituto Souza Training, 2015.

TOLEDO, et al. Qualidade: Gestão e Métodos. Rio de Janeiro: LTC, 2014. 
Recebido: 12 set. 2017

Aprovado: 15 abr. 2018

DOI: 10.3895/gi.v14n2.7048

Como citar:

CARDOSO, A. L. L.; SOUZA, Y. B. M.; MARTINS, V. W. B.; PIMENTEL, F. Q. A. Planejamento de metas

para redução de falhas no processo de distribuição de uma empresa transportadora. R. Gest. Industr., Ponta Grossa, v. 14, n. 2, p. 206-226, abr./jun. 2018. Disponível em: $\langle$ https://periodicos.utfpr.edu.br/rgi $>$.

Acesso em: XXX.

Correspondência:

Adriano Lindon Leite Cardoso

Folha 18 Quadra 08 Lote 29, Bairro Nova Marabá, Marabá, Pará, Brasil.

Direito autoral:Este artigo está licenciado sob os termos da Licença Creative Commons-Atribuição 4.0

Internacional.

(c) (i) 